\title{
Demarcating User eXperience
}

\author{
Virpi Roto ${ }^{1,2}$ \\ ${ }^{1}$ Tampere University of Technology, Human-Centered Technology, \\ Korkeakoulunkatu 6, 33720 Tampere, Finland \\ ${ }^{2}$ Nokia Research Center, P.O.Box 407, 00045 Nokia Group, Finland \\ virpi.roto@nokia.com
}

\begin{abstract}
This panel discusses the scoping of user experience as a research field. User experience is a crossing point of several disciplines, each of which tends to define user experience from their own perspective. The distinguished panelists from academia and industry represent the different perspectives to user experience: Traditional human-computer interaction, Psychology, Cognitive psychology, and Design. The goal of the panel is to get one step closer to a shared understanding of the concept of user experience.
\end{abstract}

\section{Goal}

The concept of user experience (UX) is widely used but understood in many different ways. The multidisciplinary nature of UX has provoked several definitions and perspectives to UX, each approaching the concept from a different viewpoint. UX is seen as a holistic concept covering all aspects of experiencing a phenomenon, but we are facing the point where UX becomes a too broad concept to be useful in practice. Practitioners have difficulties to understand the concept and to improve UX in their work, and researchers rather use some other term to make their research scope clear. Instead of dismissing the whole term of user experience, we believe UX can be defined to cover a certain set of cases and to make its scope clear.

There have been several activities that aim to get closer to a shared understanding of the vague concept of UX, and this panel builds on those activities. Two workshops [1,2], a Special Interest Group session [3], and an online survey [4] have been conducted to collect information on how UX professionals understand UX. In this panel, we aim to proceed from the phase of gathering broad understanding to the phase of narrowing down the concept of UX. We start to demarcate the field of UX.

\section{Topics}

The panelists first have a few minutes for presenting their position and perspective to UX. They are guided to prepare for the most intriguing and widely interesting questions about UX demarcation, for example, the ones below. The audience is encouraged to pose questions to panelists as well. 
Potential topics for discussion:

- If a university provides a study program on user experience, what do you think it should be about?

- If I am searching for a User Experience Manager to work at Nokia, what do you think the work will be about?

- What is the difference between UX and experience in general?

- What is the difference between UX and usability?

- How should we evaluate UX (from your perspective to UX)?

\section{Panelists}

The prestigious group of five panelists from academia and industry represent the different perspectives to user experience as follows.

1. Nigel Bevan, Professional Usability Services, United Kingdom Perspective: Usability, ISO definition for UX (http://www.nigelbevan.com)

2. Jettie Hoonhout, Senior Scientist, Philips, Netherlands Perspective: Industry needs (http://www.linkedin.com/in/jettiehoonhout)

3. Kristina Höök, Professor, Stockholm University, Sweden Perspective: Affective interaction (www.sics.se/ kia)

4. Ilpo Koskinen, Professor, University of Arts and Design, Finland Perspective: Design, Co-experience (http://www2.uiah.fi/ ikoskine/)

5. Gitte Lindgaard, Professor, Carleton University Ottawa, Canada Perspective: Hedonic+pragmatic UX (http://www.carleton.ca/ glindgaa)

Panel moderator: Virpi Roto, Visiting Researcher at Technical University of Tampere and Principal Scientist at Nokia Research Center, Finland.

(http://research.nokia.com/people/virpi_roto)

\section{References}

1. Law, E.L.-C., Hvannberg, E.T., Hassenzahl, M.: Proceedings of the workshop on Towards a Unified View of UX, in conjunction with NordiCHI 2006, Oslo, Norway, October 14 (2006)

2. Law, E.L.-C., Vermeeren, A., Hassenzahl, M., Blythe, M. (eds.): Proceedings of the workshop on Towards a UX Manifesto, in conjunction with HCI Conference, Lancaster, UK, September 2 (2007)

3. Law, E.L.-C., Roto, V., Vermeeren, A.P.O.S., Kort, J., Hassenzahl, M.: SIG on Towards a shared definition of user experience. In: Proceedings of ACM CHI 2008, Florence, Italy, April 2008, pp. 2395-2398 (2008)

4. Law, E., Roto, V., Hassenzahl, M., Vermeeren, A., Kort, J.: Understanding, Scoping and Defining User eXperience: A Survey Approach. In: Proceedings of ACM CHI 2009, Boston, MA, USA (April 2009) 